\title{
Hydrocele in a Peritoneal Dialysis Patient: Hernia or Leakage
}

\author{
Mei-Yu Lin ${ }^{1}$ and Chia-Chao $\mathrm{Wu}^{2}$
}

Key words: genital swelling, hernia, hydrocele, peritoneal dialysis

(Intern Med 50: 3047-3048, 2011)

(DOI: 10.2169/internalmedicine.50.6572)
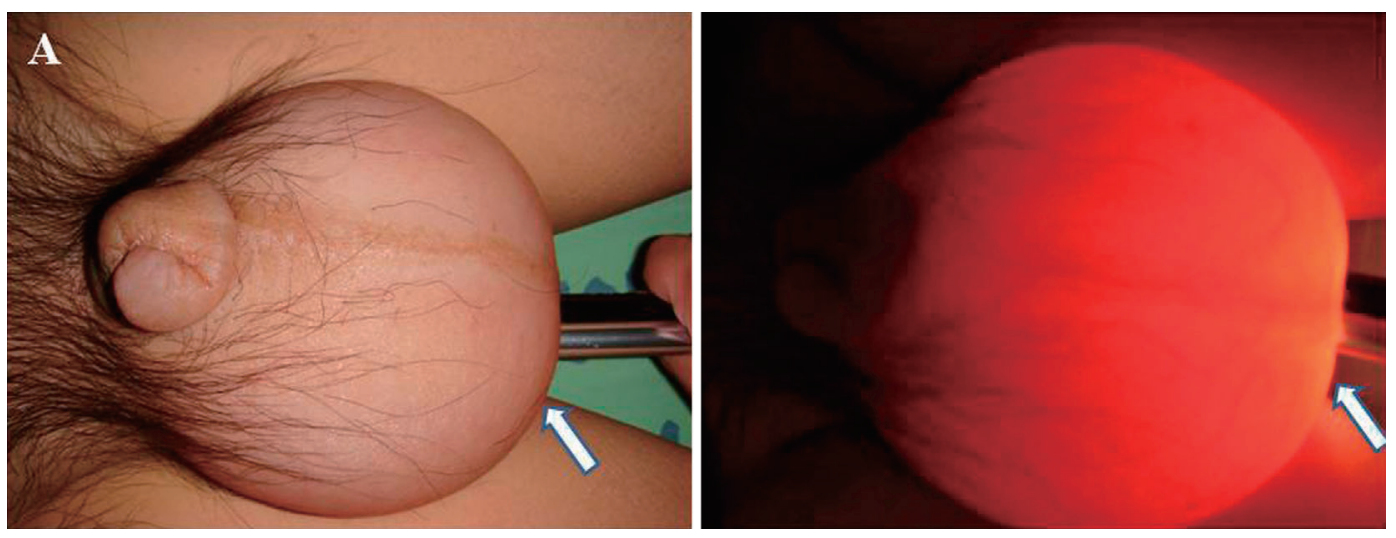

Picture 1.
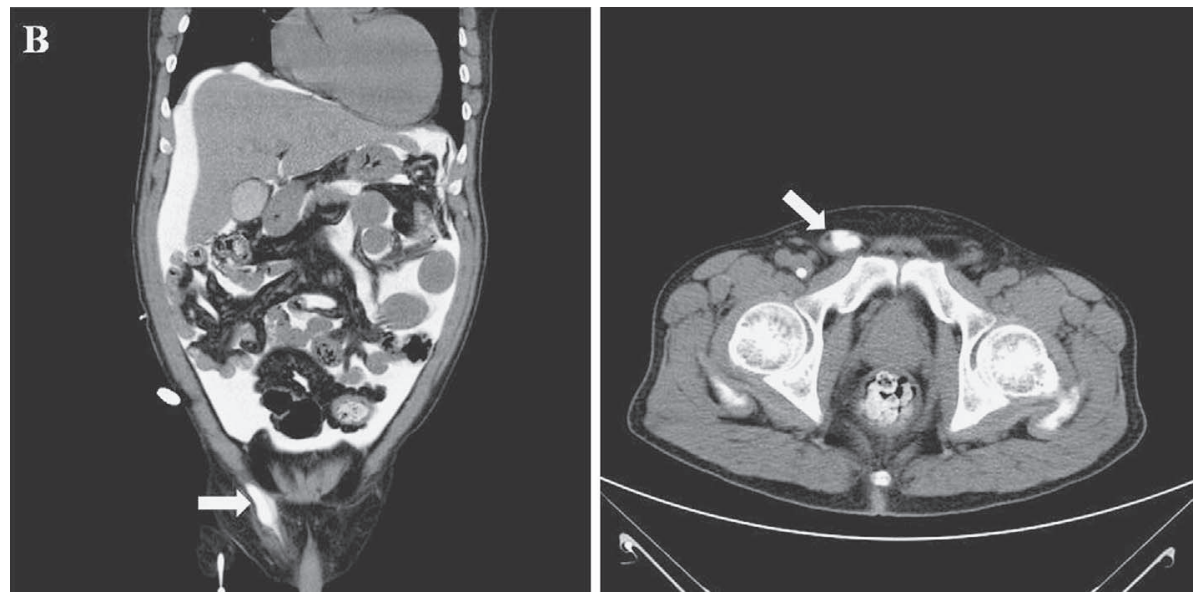

Picture 2.

A 41-year-old man with end-stage renal disease due to diabetes nephropathy received continuous ambulatory peritoneal dialysis for about one year. He developed genital swelling and decreased dialysate fluid drainage over one week.
Transallumination of the scrotum demonstrated fluid collection (Picture 1). Computed tomography peritoneography showed contrast media in the right spermatic cord (Picture 2). Surgical exploration disclosed inguinal hernia; it

${ }^{1}$ Division of Nephrology, Department of Medicine, Cardinal Tien Hospital, Taiwan and ${ }^{2}$ Division of Nephrology, Department of Medicine, TriService General Hospital, National Defense Medical Center, Taiwan

Received for publication September 16, 2011; Accepted for publication September 21, 2011

Correspondence to Dr. Chia-Chao Wu, wucc@ndmctsgh.edu.tw 
was repaired. The swelling subsided and peritoneal dialysis was reinstituted after the operation.

Patent processus vaginalis causing a communicating hydrocele, inguinal hernia and abdominal wall leak should be considered in genital swelling (1). Computed tomography peritoneography is accurate for diagnosing peritoneal defects, by using dialysis fluid mixed with contrast. It facilitates the diagnosis and surgical planning by demonstrating the site, size and anatomy (2). Due to the high recurrence rate, even small hernias should be repaired and early detection can prevent more serious complications like small bowel strangulation or intestinal incarceration.
The authors state that they have no Conflict of Interest (COI).

\section{References}

1. Tzamaloukas AH. Scrotal edema in patients on CAPD; causes, differential diagnosis, and management. Dial Transplant 21: 581584, 1992.

2. Hawkins SP, Homer JA, Murray BB, Voss DM, van der Merwe WM. Modified computed tomography peritoneography: clinical utility in continuous ambulatory peritoneal dialysis patients. Australas Radiol 44: 398-403, 2000.

(C) 2011 The Japanese Society of Internal Medicine http://www.naika.or.jp/imindex.html 